\title{
ARQUIVOS POÉTICOS: O FIO DA ESCRITA
}

\author{
Telma Borges da Silva*
}

RESUMO:

Através do conceito de arqueologia e de arquivo, investigase o de ocidente no poema "O Sentimento dum Ocidental", de Cesário Verde e suas relações com literatura portuguesa, o poesia de Baudelaire e o cinema e poesia brasileiros.

PALAVRAS-CHAVE: ocidente, modernidade, arqueologia, arquivo, tradição.

Este trabalho é um território descontínuo no qual cintilam constelações poéticas marcadas pela lógica do acontecimento. Este que se produz num espaço/tempo que se interrompe constantemente para se opor à visão linear da história. Deseja compreender, a partir de uma poética das sensações, o modo como Cesário Verde dialoga com a literatura portuguesa: Camões, a Geração de 70 e Fernando Pessoa; com Charles Baudelaire e a poesia e cinema brasileiros.

$\mathrm{Na}$ experiência poética das ruas, inaugurada por Baudelaire, realiza-se o imbricamento de linguagens próprias a saberes se fazem no espaço aberto da troca e do trânsito. Na condição de escrita de contestação, a poesia de Verde se alia à do poeta francês para problematizar um processo de modernização marcado pelo cientificismo de feição iluminista. Caracteriza-se como uma escrita aberta aos sentidos/sensações apreendidos na cena da cidade moderna à medida que o sujeito se liberta de uma percepção regulada do que está à sua volta. Esse movimento poético quebra com a organicidade ocidental, para se projetar no espaço/tempo do vir a ser. Vários são os acontecimentos que perpassam esse corpo poético: vestígios do passado a perturbarem a ordem fixada do presente; ações em devir, que desencadeiam séries, modulações que retornam no texto de outros poetas, numa busca incessante do que se passa nesse espaço da dispersão.

* Mestre em Letras: Estudos Literários (Área de concentração: Teoria da Literatura), 2000. 


\section{EM TESE}

Belo Horizonte, v. 5, p. I-305, dez. 2002

A segunda metade do século XIX testemunhou mudanças profundas no cenário europeu. Portugal, na retaguarda dessas alterações, é influenciado por esses acontecimentos. Sob a égide de uma racionalidade ocidental, a ciência é encarada como único conhecimento possível. Na era da técnica e da implantação de um sistema de produção seriado, o homem é entendido como uma minúscula engrenagem de uma máquina social ávida por ampliar ainda mais os seus dominios técnicos.

Nesse contexto, o discurso poético, como o de Charles Baudelaire e Cesário Verde surge como um modo de reação capaz de incomodar, de deslocar de seu lugar cômodo a burguesia, classe social em ascendência nesse período. Cesário, também membro dessa nova classe, se apropria de seus modos e suportes discursivos para minar os propósitos burgueses de uma modernidade que pretende se garantir à custa de um desejo perverso de eliminar aqueles que não se inseriam no sistema com a mesma força.

Ao se aperceber dessas questões, o poeta português constata a presença de duas Lisboas: uma marcada pelos traços modernizantes e a outra submersa à primeira, que esconde em suas dobras as réstias do passado glorioso. Na interseção desses dois planos geográficos, ele encontra uma cisão onde comporá uma cartografia crítico-poética de Lisboa na medida em que abre e amplia o arquivo poético da tradição, pela via camoniana e ironiza o modo pelo qual os vestígios do passado adentram 0 presente.

No contexto de uma modernidade crítica, Verde, que em vida publica apenas em periódicos, sofrerá inúmeros ataques da parte de seus contemporâneos. Esses mesmos periódicos que, não raras vezes, publicaram seus poemas, trazem à tona alfinetadas, como esta, impressa no "Dário de Notícias", relativa ao poema "Num Bairro Moderno": "todos os poetas devem ter uma gaveta profunda, ampla, extraordinária, consagrada às deusas da modéstia e do bom senso, a que se devem sacrificar as composições como esta, em lugar de se apresentarem à luz pública."

Certamente Cesário fora bastante incompreendido em seu tempo pois, ao contrário da poesia que se fazia à época, a sua estava aberta aos rumores e sensações do espaço heterotópico da rua. Não obstante algumas menções a espaços fechados, como se pode ver no poema "Contrariedades". Ao privilegiar o espaço da 
rua, o poeta faz circular por ele os: carpinteiros, calafates, escaleres, obreiras, varinas, velhinhas, crianças, mulheres de dom, o clero, costureiras, floristas, as burguesinhas do catolicismo, freiras, forjadores, padeiros, caixeiros, tristes bebedores, dúbios caminhantes, guardas, professor de latim, imagens que povoaram "0 Sentimento dum Ocidental".

Não só povoaram numa dimensão poética como, de fato, se submeteram ao fluxo galopante da modernização. Construíram o 0cidente, depois foram escondidos em suas dobras. Ao buscar motivos para sua poesia, Cesário procede como um arqueólogo que escava em busca de restos que possam dizer de que modo o passado opera com 0 presente. Ou seja, o passado, em sua concepção, deve ser agregado ao presente para perturbar uma ordem supostamente estabelecida pelas leis racionais postuladas pelo conhecimento científico e ordenador daquilo que acredita não ter ordem.

Nesse sentido, a poesia de Cesário Verde é revolucionária, mas de uma revolução que pretende dar voz ao oprimido, o que vai de encontro aos propósitos da Geração de 70. Essa Geração, na figura de seus principais representantes: 01iveira Martins, Antero de Quental, Eça de Queirós tinha a revolução como princípio capaz de alterar profundamente a cultura portuguesa.

Dando continuidade a um processo iniciado com a "Questão Coimbrã ou "Do Bom Senso e do Bom Gosto", essa Geração coloca em evidência uma voz poética com timbres modernos; longe dos moldes sentimentais românticos. 0 programa das "Conferências do Casino" anuncia o compromisso revolucionário reservado à poesia desse tempo, para uma nova concepção de poeta e para, segundo Antero de Quental, um "espírito livre de jugos, o pensamento livre de preconceitos e respeitos inúteis, o coração livre de vaidades, incorruptível e itemerato".

Os intelectuais da "Geração de 70" empreenderam um projeto de registrar, pelo viés do literário e histórico, a sociedade portuguesa e suas mazelas sociais. Mas é Cesário Verde entretanto, que se detém no caráter marginal, submerso nos porões da modernidade. Ao revelar essa face escondida do 0cidente, o poeta dialoga criticamente não só com a Geração de 70, bem como com Charles Baudelaire.

Como com os aspectos cotidianos, contingentes da sociedade, o poeta realiza um enlace intertextual com o poeta francês, que se contrapõe ao realizado pela geração que o precedeu. Cesário Verde e Baudelaire têm a qualidade de um olhar 


\section{EM TESE}

Belo Horizonte, v. 5, p. I-305, dez. 2002

que não repousa sobre a paisagem contínua de um espaço articulado. Seu olhar se envereda pelos engendramentos descontínuos, desmantelados pela tensão causada por duas imagens urbanas circunscritas num único espaço.

No contexto de Cesário Verde, o país experimenta sensível instabilidade política e econômica. Mas, a partir da década de 60 do século XIX, começam a ser percebidas transformações em todos os sentidos: cultural, urbano, político e tecnológico.

Pode-se dizer que Portugal inicia um processo de modernização inspirado na reestruturação do traçado arquitetônico e cartográfico de Paris e outras capitais européias. Para assumir tal feição, o país intenta soterrar os vestígios do passado que se agregam ao presente. Em contraposição e essa concepção de moderno, Cesário Verde se apropria do conceito de moderno cunhado por Baudelaire, que se define por uma expressão hodierna e contingente e outra eterna e imutável. 0 poema "0 sentimento dum 0cidental" se estrutura a partir dessa concepção e delineia a movimentação das multidões heterogêneas pelas ruas: trabalhadores que se misturam aos rumores e aromas urbanos, que transitam sob o clarão das luzes artificiais.

Na sua caminhada, depara com monumentos, como o de Camões a se insinuarem na cena moderna como uma réstia épica. Nesse deambular pelo solo ocidental, sua poesia recolhe essas réstias como modo de pertencer, mas também de denunciar a perversidade logocêntrica de unidade e igualdade.

0 0cidente, então, se revela em quatro dimensões: é uma chaga aberta a evidenciar a dor humana; é um desejo de uniformidade que tenta eliminar o diferente; é uma cartografia tensionada pela fenda que se estabelece entre o 0cidente visto e o planejado no compasso e no esquadro; é também uma caverna escura, semelhante à caverna de Platão, uma eterna noite que pretende aprisionar uma multidão de ricos, pobres, velhos, crianças, loucos, prostitutas, bebedores, iletrados e eruditos. Tudo em nome da razão tecnológica da qual o homem é apenas mais uma peça que faz girar as calhas da engrenagem moderna.

0 extremo dessa percepção encontra-se no poema "Ode Triunfal", de Álvaro de Campos, heterônimo pessoano. Esse poeta leva às últimas conseqüências essa cisão do sujeito e do espaço apreendidos na poesia de Verde. Com os sentidos 
prenhes de ruídos, cheiros, aromas, cores espalhados pelo espaço da rua, Campos se deixa penetrar pelo sensacionismo da cidade, onde borbulham sentimentos cuja percepção só é possível quando o sujeito se deixa surpreender pelos sentidos multifacetados da metrópole forjada em metais, motores, artefatos artificiais com os quais o homem heróico, ser pensante e idealizador desse espaço, desaparece para ser transformado numa pequena partícula desse corpo urbano.

0 trabalho com a linguagem em "Ode Triunfal" é pertinente com a dimensão heterotópica da rua. Desencantada, parece fazer uma apologia do desencanto à civilização ocidental no século XX. Essa metamorfose desencadeada no mundo ocidental, flagrada por Verde no século XIX e por Campos no século XX exacerba um sentimento civilizatório que coloca os dois poetas não só como produto dessa civilização, mas como aqueles que, a partir do exercício da escrita, realizam um ato de protesto contra ela e anunciam esse sentimento sugerido pelo título do poema "0 sentimento dum Ocidental" como um sentimento de todo o 0cidente diante do processus de modernização européia.

No primeiro poema, ocidental é um adjetivo que qualifica; um sentimento coletivo expresso metaforicamente pelo cenário que percorre o poeta: Lisboa. Assistese aí a uma inversão do jogo: ao invés de ser suplantada pela Europa, a capital portuguesa investe ironicamente sobre o continente.

"Ode triunfal" é uma manifestação que beira a epopéia. Assim como em Cesário Verde, uma épica às avessas em que o adjetivo triunfal tem a dimensão pleonástica, sugestiva de emoções excessivas, além da capacidade humana de suportá1as. 0 triunfo é a expressão irônica da derrota. Vencido, o herói épico deixa de povoar um imaginário grandiloqüente; torna-se partícula que capta os sentidos da metrópole forjada em metais. A poesia é, nesse espaço, uma potencial idade questionadora da razão ocidental.

Como um corpo cindido que reverbera por espaços inusitados, flagro algumas nuances de Cesário na poesia e cinema brasileiros. Revisitando minimamente o arquivo da tradição com a qual Verde dialoga e na qual insere seus fios, percebo uma apropriação desses fios em determinados momentos da tradição literária brasileira. 


\section{EM TESE}

Belo Horizonte, v. 5, p. I-305, dez. 2002

Cabe antes, entender o conceito de arqueologia e arquivo estabelecidos por Foucault e de que modo eles contribuem para uma compreensão das relações de Cesário com o Brasil. Para Michel Foucault, a arqueologia é uma saber que se nutre de vestígios acumulados aleatoriamente, não é um retorno à lucidez precária e extinta da origem; sim "um abandono da história das idéias". Tal afirmativa parece negar o conceito de Ocidente enunciado por Platão no mito da Caverna, delineador do nascimento da ratio ocidental.

Como desdobramento desse conceito, o arquivo é o elemento que define 0 funcionamento e a atualidade de um determinado sistema de discurso; guarda os monumentos de uma cultura, sempre tangenciados por outros tempos e paradigmas discursivos. Assim como argumenta Foucault, os artistas brasileiros deslocam Cesário da sua condição de arquivo, monumento a ser reescrito, em que novos fios são tecidos para um novo reengendramento desse arquivo.

0 filme Alma Corsária, de Carlos Reichenbach traz para o centro da cena um olhar para Portugal que tem o sentido de proceder a uma execução ritual do pai, constatando a sua presença enquanto tradição a ser constantemente reescrita. Exemplo disso é o livro que escrevem a quatro mãos os protagonistas: Sentimento Ocidental. Não é mais o sentimento de um ocidental europeu, mas um sentimento de todo o Ocidente, que transgrediu as fronteiras transatlânticas.

No poema "Desafinadamente", de Felipe d'01 iveira, o poema "Contrariedades", de Verde se oferece como mote para o poeta brasileiro. Mas a imagem da tísica, nova musa da poesia moderna, é transubstanciada no próprio fazer poético que perdeu a verve e o rigor irônicos que percorreram a poesia de Cesário.

Aníbal Machado, por sua vez, assume a voz poética do autor português, pois adota o pseudônimo de António Verde. Esse nome que ficcionaliza de maneira híbrida o nome de dois poetas portugueses: Cesário Verde e António Nobre funcionam como uma máscara que assinala um segundo nascimento proporcionado pela escrita. Ao realizar a fusão do nome desses dois poetas, Aníbal Machado o faz também com o tema da morte que é recorrente na obra dos dois poetas que homenageia. Mas, enquanto em Cesário a escrita é um modo de adiar a morte, em Nobre escrever é uma maneira de abreviar a vida. Em Aníbal, a morte é, ao mesmo tempo, o grande prazer de todos os 
sentidos, um encontro com a racionalidade. É também uma fatalidade da qual, por vezes, deseja escapar.

0 fio da obra de Cesário Verde que tangencia a obra de Manuel Bandeira, aparece no poema "Improviso" e revisita a tradição literária portuguesa: do trovadorismo de D. Dinis ao saudosismo de Teixeira de Pascoais. Nesse cordel laudatório à poesia portuguesa, Bandeira, num requinte irônico, insere a figura de Cesário Verde, a quem o verdor é uma característica que fura a tessitura dessa tradição para renovar suas páginas literárias.

Nessa mesma perspectiva laudatória, no texto de Murilo Mendes "Murilograma a Cesário Verde" há uma síntese dos temas mais expressivos na obra de Cesário: a cidade, o campo, a terra, o urbano, a rua, o caráter épico de alguns de seus poemas. Entretanto, o que parece atrair mais a atenção do escritor mineiro é a tísica do poema "Contrariedades", que se configura como a musa da poesia moderna. Rompendo com os estereótipos românticos, a tísica sobrevive do trabalho que realiza com o ferro de engomar. Ferro este que se alia à "acesa lira" que Murilo sinaliza como fagulha rebelde, extravagante de Cesário Verde, por isso moderna. Modernidade esta que se compromete em combater a peste que às vezes ronda a linguagem.

0 poeta nordestino João Cabral de Melo Neto, no poema "0 sim contra o Sim" destaca da poesia de Verde a plasticidade que the era tão peculiar. Tendo como pano de fundo o poema "Num Bairro Moderno", Cabral evidencia os tons claros que Cesário nele utiliza como resultado do "lavar, relavar, e enxaguar para dar maior luminosidade e expor o mundo do homem tísico, do comércio vivo, todos produtos da modernização. Essa clareza também pode ser atribuída ao rigor crítico que percorre toda a poesia do poeta português. Esse rigor prima por dar nitidez e visibilidade aos contrastes que fazem parte da rua moderna.

0 poeta baiano Waly Salomão escreve dois textos nos quais presta uma homenagem a Cesário: "Tal qual Paul Valéry" e "0 Cólera e a Febre". No primeiro, revela a poesia enquanto um saber partilhado com os antigos e com os vivos: é um saber que não se faz sozinho; os fios que o compõem se distinguem na Babel feliz da contemporaneidade, pois o poeta os nomeia: Sá de Miranda, Camões, Cesário, João, Cabral, Augusto, Ashbery. No segundo poema, como diz o próprio Salomão: "um pastiche 


\section{EM TESE}

Belo Horizonte, v. 5, p. I-305, dez. 2002

pálido e mal cesurado de Cesário Verde", essa estratégia de apropriação explicita um modo de escrever à moda de, "como busca e afinamento de uma escritura própria". A rua continua sendo o espaço heterotópico, mas dela desapareceram os escaleres, as varinas, os dentistas, a chusma clerical. Foram todos transformados em pontos luminosos a emanarem luz do lusco-fusco que, na perspectiva do pastiche, esbarra no último verso de Salomão e primeiro de Cesário: "Nas nossas ruas, / ao anoitecer".

No Ocidentes dum Sentimental, livro de Maurício Vasconcelos "0 Sentimento dum 0cidental" aparece como uma constelação sobre a qual se realiza um grafite cujo objetivo é transgredir o poder monumental da tradição. 0 poema de Verde transformase em página/muro para que Maurício grafite o texto de Cesário. Assim, o poeta desestabiliza o lugar colonizado da página e muda a realidade suscitada pelo texto. Os emparedados d"0 Sentimento dum Ocidental" são desenclausurados, transformam-se em surfistas rodoviários a se apropriarem do monumento deambulante.

0 poema reescrito transforma-se em página da cidade, rua que ganha novos transeuntes. 0 poema de Cesário, como parte desse cenário, invade em páginas soltas o livro de Maurício. É Sinal de transgressão do poder que reside na língua e na ordem estabelecida. Ao ser inserido como entalhe nas páginas poéticas de Os ocidentes dum Sentimental, Verde deixa de ser o meandro mutilado de um discurso, para dialogar com as fendas que Maurício provocou nos muros do poder, da tradição. Tornam-se grafite móvel, pois deslocam, surfam entre letras e fotografias, compondo a nova cena dos mundos ou do mundo no qual o leitor é chamado a ser um grafiteiro para aumentar o horizonte de visibilidade do monumento, que se assume como poema da rua, da cidade, do Ocidente.

A arqueologia, como conceito, foi a chave operacional para a compreensão do texto de Verde e suas relações com o 0cidente. Não revelou a origem nem os seguidores de Cesário, pois é um arquivo cinzelado por onde passam as linhas de força que conduzem a poesia para o espaço da rua, lugar constantemente atravessado por uma multiplicidade de sensações.

Nesse percurso arqueológico em que me enveredei por múltiplos arquivos, a genealogia e a história estabeleceram um impasse. Não se pretendeu buscar a identidade primeira que se projetou na obra de Verde, nem mesmo buscar pistas ou 
vestígios de sua obra no futuro. A reflexão e a própria estrutura desse trabalho apontaram para a necessidade de lidar com o que se passou na dispersão, contida na própria prática e recepção do moderno em língua portuguesa, dos fins do século XIX aos fins do século XX.

No desejo de realizar uma arqueologia crítica, como uma das inúmeras possibilidades de ler a tradição poética com a qual Cesário Verde dialoga, tentei adivinhar o movimento das mãos que, com uma agulha, furavam a tessitura da tradição. $E$, no espaço da urdidura por onde passa o fio inovador, analisei o momento em que a trama da tradição foi perfurada por um instinto de novidade capaz de revisitá-la e acrescentar os fios de um trabalho crítico para composição de novos arquivos.

Assim, a agulha imantada de Cesário Verde, com a qual recolhi vestígios que antecederam e sucederam sua poética, serviu de orientação para que se configurasse uma arqueologia poética incessante, que sofre de uma vertigem essencial, garantia de sua continuidade num espaço/tempo formado por sucessivas rupturas, como essas vividas pelo Ocidente nos dois últimos séculos.

Nessa perspectiva, as páginas poéticas de Cesário Verde se multiplicam numa comunicação com outras manifestações cujos cortes transversais que ali se fazem reorganizam os inúmeros fragmentos, al inhavando-os sem a pretensão de construir uma totalidade. A unidade de sua obra parece, então, se fazer a partir daquilo que dela escapa, que reverbera fora do seu lugar. É um desvio do modelo, pois a agulha imantada que a costura aponta sempre outros caminhos, permitindo inventar pespontos autônomos e imprevistos.

ABSTRACT :

Through the concept of archeology and archives, it is investigated the concept of the west in Cesário Verde's "O Sentimento d'um Ocidental" and its relation with Portuguese literature, Baudelaire's poetry and Brazilian poetry and cinema.

KEY WORDS: west, modernity, archeology, archives, tradition. 
ALMA corsária. Direção de Carlos Reichenbach. São Paulo: Desenove Som e Imagens, 1994. $110 \mathrm{~min}$, colorido. (Fita de vídeo -VHS).

BANDEIRA, Manuel. Mafuá do malungo: versos de circunstância. Rio de Janeiro: Livraria São José, 1954. Obra do Acervo Henriqueta Lisboa.

CALVIN0, Italo. Seis propostas para o próximo milênio. 2. ed. Trad. Ivo Barroso. São Paulo: Companhia das Letras, 1999.

COMPAGNON, Antoine. O trabalho da citação. Trad. Cleonice P. B. Mourão. Belo Horizonte: Editora UFMG, 1996.

DELUMEAU, Jean. História do medo no ocidente - 1300-1800: uma cidade sitiada. Trad. Maria Lúcia Machado. 3.ed. São Paulo: Companhia das Letras, 1996.

FOUCAULT, Michel. A arquelogia do saber. 4. ed. Trad. Luiz Felipe Baeta Neves. Rio de Janeiro: Forense Universitária, 1995.

MACHADO, Aníbal. Último Festim. In: Vida de Minas. Belo Horizonte: Arquivo Público Mineiro, 1915. Revista do Acervo de Escritores Mineiros.

MELO NETO, João Cabral de. Antologia poética. Rio de Janeiro: Sabiá, 1969.

MENDES, Murilo. Convergência. In: Poesia completa $e$ prosa. Rio de Janeiro: Nova Aguilar, v. II, 1997.

OEHLER, Dolf. Quadros parisienses. Estética antiburguesa em Baudelaire Daumier e Heine (1830-1848). Trad. José Marcos Macedo e Samuel Titan Jr. São Paulo: Companhia das Letras, 1997.

PESSOA, Fernando. Poesias de Álvaro de Campos. In: Obras completas de Fernando Pessoa. Lisboa: Ática, [s.d.].

REIS, Carlos. As conferências do Cassino. Lisboa: Publicações Alfa, 1990.

SALOMÃo, Waly. Algaravias: câmara de ecos. São Paulo: Editora 34, 1996.

SALOMÃO, Waly. Armarinho de miudezas. 2. ed. Salvador: Fundação Casa de Jorge Amado, 1993.

SCHNEIDER, Michel. Ladrões de palavras: ensaio sobre o plágio, a psicanálise e o pensamento. Trad. Luiz Fernando P. N. Franco. Campinas: Editora da UNICAMP, 1990.

SILVEIRA, Pedro da. (Org.). Cesârio Verde (1855-1886): catálogo de exposição comemorativa do primeiro centenário da sua morte. Lisboa: Biblioteca Nacional, 1986.

VASCONCELOS, Maurício Salles. Ocidentes dum sentimental. Belo Horizonte: Edições Orobó, 1998.

VERDE, Cesário. O livro de Cesário Verde. 4. ed. Lisboa: Biblioteca Ulisséia de Autores Portugueses. Introd. Maria Ema Tarracha Ferreira, 1995. 